\title{
WELL PRESSURE BEHAVIOR FOR A VERTICAL WELL IN A GAS CONDENSATE NATURALLY FRACTURED RESERVOIR
}

Freddy Humberto Escobar', Humberto García Rocha², Ivan Mauricio Suaza ${ }^{3}$, and José Humberto Cantillo ${ }^{4}$

1 Universidad Surcolombiana, e-mail: fescobar@usco.edu.co

${ }^{2}$ Universidad Surcolombiana, e-mail: kinino11@hotmail.com

${ }^{3}$ Universidad Surcolombiana, e-mail: suaza82@yahoo.es

${ }^{4}$ Ecopetrol S.A. - ICP, e-mail: jose.cantillo@usco.edu.co

Keywords Capillary number, interfacial tension, relative permeability, interporosity flow parameter, storativity coefficient, condensate saturation

\section{Abstract}

The complex behavior exhibited by gas condensate reservoirs due to the existence of a two-phase system: reservoir gas and liquid condensate and its implications plus the nature of heterogeneities is the subject of the present article which involves handling of reservoir engineering concepts subject to be interpreted, so that by coupling them with pressure transient analysis using a compositional simulator, we can obtain some patterns which lead to facilitate the understanding of the reservoir's dynamics.

Great volumes of fluids are stored in Naturally Fractured Reservoirs (NFR). Simulation of this type of deposits presents great challenges, from not only the geomechanical point of view but also the thermodynamical modeling of the different phases flowing throughout the fracture system.

In this work, we present an attempt to model a gas condensate formation involving the implications of relative permeabilities to observe their effect on the flow behavior once pressure finally falls below the dewpoint and the effect of the capillary number on the fluid flow phenomena in the near-wellbore region. Interpretation of the pressure test is conducted by the TDS technique.

\section{Introduction}

Gas condensate reservoirs are truly important to the oil industry because of the quality of the recovered oil, and then, its price. Barrios et al. (2003), Bnegherbia and Tiab (2002), Fevang and Singh (2000) and Gringarten et al. (2000) have made good contributions to simulation and well test analysis of gas condensate systems. An inadequate exploitation of these reservoirs cause condensate formation in the near-wellbore region when the pressure falls below the dewpoint value which leads to a sharp productivity reduction since the condensate also reduces relative gas permeability. Retrograde condensation has also an associated problem: the precipitation of the heavier compounds becomes the mixture poorer in these compounds causing a variation of fluid composition and a change in flow parameters. These effects increase the complexity of gas condensate well test interpretation. Additionally, the fractured nature of the reservoir contributes to reservoir characterization and forecasting to be a challenging milestone to the oil industry. Dealing with these systems requires representative reservoir model construction to accurately handle fracture-matrix systems and their interaction. In this work we extended the work of Munoz et al. (2006) to naturally fractured occurring formations.

\section{Modeling}

To perform the simulation experiments Suaza and Garcia (2006) employed a compositional commercial Simulator to study the behavior of a vertical gas condensate well producing at constant rate in the center of a circular naturally fractured reservoir which main input data are given in table 1. A logarithmic radial grid with 100 cells in the i-direction was used to better capture the local details around the well. After a sensitivity análisis, we found that 16 layers in the $j$-direction was enough for an adequate reservoir-fluid description. Several scenarios were studied with different values of gas rate, capillary number, storativity coefficient and interporosity flow parameters. In all the cases, initial reservoir pressure was set higher than the dewpoint pressure to ensure monophasic flow in region III.

We used a mixture of 14 compounds as reported by Fevang and Singh (2000) and the three-parameter Peng and Robinson equation of state to simulate phase behavior.

Corey's correlation including their dependence with not only fluid saturation but also capillary number were used. To match the experimental data the end-point relative permeabilities and the exponents $n_{0}$ and $n_{g}$ are employed:

$k_{r o}=k_{r o}^{o}\left(\frac{S_{o}-S_{o r}}{1-S_{o r}-S_{g r}-S_{w c}}\right)^{n_{o}}$

$k_{r g}=k_{r g}^{o}\left(\frac{S_{g}-S_{g r}}{1-S_{o r}-S_{g r}-S_{w c}}\right)^{n_{g}}$

The commercial Simulator has the following three models for estimation of the capillary number:

$$
\begin{array}{r}
N_{c j}^{(1)}=\frac{v_{g} \mu_{g}}{\sigma} \\
N_{c j}^{(2)}=\frac{k k_{r v j} \Delta P_{j}}{\sigma L}
\end{array}
$$




$$
N_{c j}^{(3)}=\left(2 \phi S_{j} k k_{r v j}\right)^{0.5} \frac{\Delta P_{j}}{\sigma}
$$

\section{Simulation Results}

\section{Effect of Gas Flow Rate}

Gas condensate saturation for five different gas flow rates was determined and reported in Fig. 1. As the gas rate increases, the dewpoint pressure shows up earlier since the pressure drop is accelerated, in other words, as the flow rate increases the size of region III decreases. Notice the existence of a higher condensate saturation in the fracture than in the matrix.

Fig. 2 presents the behavior of pressure and pressure derivative for different flow rates. As flow rate increases both curves are shifted upwards since skin factor increases due to the increment of non-Darcy effects ("turbulence"). Curves for gas rate of $13000 \mathrm{Mscf} / \mathrm{d}$ presents a better behavior than the one for $14000 \mathrm{Mscf} / \mathrm{d}$ where skin is higher. It is observed that as the rate increases the biphasic zone shows up earlier because the dewpoint pressure is reached faster.

\section{Effect of Capillary Number}

For this effect, we take into account (1) the effect of condensate flow and (2) the estimation of the naturally fracture reservoir parameters by using the TDS technique, Engler an Tiab (1996).

\section{Effect of condensate flow}

The well pressure behavior with and without considering capillary number effects is given in Fig. 3. The reader can observe a favorable effect added by the capillary number since a lower pressure drop is registered, and therefore, there will be a lower condensate saturation. Also, the pressure trend is smoother since well damage is smaller. From $100 \mathrm{hrs}$ the pressure difference between the two curves is practically constant and about $130 \mathrm{psi}$.

Fig. 4 presents the saturation profile with and without capillary number effects for the same dewpoint pressure. It was concluded that the Nc contributes to a condensate saturation reduction around the well and reservoir. We observe in Fig. 4 that the condensate saturation in the matrix suffers revaporization due to the fluid depletion inside the fracture, and then, this is restored from the matrix.

Fig. 5 shows the gas relative permeability, $k_{\mathrm{rg}}$ curve whether or not capillary number effects are included. A maximum value, $k_{\mathrm{rg}}$ $=1$, corresponds to the monophasic flow zone (region III) with a length of $1863.2 \mathrm{ft}$ which indicates that the dewpoint pressure is located to $136.8 \mathrm{ft}$ from the well. The capillary number effect increases the gas relative permeability around the well and the reservoir. $k_{r g}$ is greater in the matrix than the fracture since fluid movements are restricted by the space.
The behavior of pressure and pressure derivative including or not capillary number effects is reported in Fig. 6. Only one phase is present during the first radial flow regime and during the matrix-fracture transition dominated period. Once the second radial flow develops the condensate has reached its critical value and begins flowing simultaneously with gas. This phenomenon is more evident when capillary effects are excluded since condensate mobility increases.

Fig. 7 presents the pressure behavior for different Nc's. The lower Nc the higher the reservoir's depletion.

Fig. 8 and 9 indicate that as the capillary number increases, condensate saturation reduces due to the reduction of interfacial tension. It causes an increment of the gas relative permeability.

Estimation of Naturally fractured reservoir parameters

Synthetic data reported in Fig. 6 were simulated with the following reservoir and fluid information:

$$
\begin{array}{lll}
q=1764 B & r_{w}=0.25 \mathrm{ft} & c_{t}=1 \times 10^{-5} \\
{[=0.1808 \mathrm{cp}} & h_{m}=90 \mathrm{ft} & i_{m}=0.188 \\
B=2.04 \mathrm{bbl} / \text { STB }_{\mathrm{f}}=10 \mathrm{ft} & \mathrm{i}_{\mathrm{f}}=0.012
\end{array}
$$

Considering Nc effects and applying TDS technique, Engler and Tiab (1996):

$$
\begin{aligned}
& k_{f b \underline{\underline{o}}}=\frac{70.6 q \mu B}{h\left(t^{*} \Delta P^{*}\right)_{r_{1}, r 2}} \\
& \omega=0.15866\left\{\frac{\left(t^{*} \Delta P^{\prime}\right)_{\min }}{\left(t^{*} \Delta P^{\prime}\right)_{r}}\right\}+0.54653\left\{\frac{\left(t^{*} \Delta P^{\prime}\right)_{\min }}{\left(t^{*} \Delta P^{\prime}\right)_{r}}\right\}^{2}
\end{aligned}
$$

$\lambda=\frac{42.5 h c_{t} \bar{\phi} r_{w}^{2}}{q B}\left(\frac{t^{*} \Delta P}{t}\right)_{\min }$

Where:

$$
\begin{aligned}
& \bar{\phi}=\frac{\left[\left(\phi_{m} * h_{m}\right)+\left(\phi_{f} * h_{f}\right)\right]}{\left(h_{m}+h_{f}\right)} \\
& s=\frac{1}{2}\left[\left(\frac{\Delta P}{t^{*} \Delta P^{\prime}}\right)_{r 1}-\ln \left(\frac{k_{f b o n} t}{\left(\phi c_{t}\right)_{t} \mu r_{w}^{2}} \frac{1}{\omega}\right)+7.43\right] \\
& s=\frac{1}{2}\left[\left(\frac{\Delta P}{t^{*} \Delta P^{\prime}}\right)_{r 2}-\ln \left(\frac{k_{f b o \underline{2}} t}{\left(\phi c_{t}\right)_{t} \mu r_{w}^{2}}\right)+7.43\right]
\end{aligned}
$$


From Fig. 6, read $\left(t^{*} \text { ? } \mathrm{P}^{\prime}\right)_{\mathrm{r} 1}=\left(\mathrm{t}^{*} \text { ? } \mathrm{P}^{\prime}\right)_{\mathrm{r} 2}=12.11 \mathrm{psi}, \mathrm{t}_{\min }=1.49$ hrs, $\left(\mathrm{t}^{*} \text { ? } \mathrm{P}^{\prime}\right)_{\min }=2.95 \mathrm{psi}, \mathrm{t}_{\mathrm{r} 1}$

$=0.007 \mathrm{hrs}, ? \mathrm{P}_{\mathrm{r} 1}=129.3 \mathrm{psi}, \mathrm{t}_{\mathrm{r} 2}=35.6 \mathrm{hrs}, ? \mathrm{P}_{\mathrm{r} 2}=200.4 \mathrm{psi}$. $\mathrm{k}_{\mathrm{t} \_\mathrm{O}}=37.9 \mathrm{md}, ?=0.071$ and, $=2.48 \times 10^{-7}$ were obtained, respectively, using Eqs. 6 through 9. Using Eqs. 10 and 11, skin factors of -0.49 and -0.49 were calculated, respectively, from the first and second radial flow regimes.

Considering Nc effects values of $\left(t^{*} \mathrm{P}^{\prime}\right)_{\mathrm{r} 1}=12.84 \mathrm{psi}$ and $\left(\mathrm{t}^{*} \mathrm{P}^{\prime}\right)_{\mathrm{r} 2}$ $=54 \mathrm{psi}$ were read and Eq. 6 led to estimations of $\mathrm{k}_{\mathrm{fb} 。}=35.7$ and $8.5 \mathrm{md}$, respectively. Other parameters obtained from the pressure and pressure derivative plot of Fig. 6 are $t_{r 1}=0.007$ hrs, $P_{r 1}=129.3 p s i, t_{\min }=1.44 \mathrm{hr}$, and $\left(t^{*} P^{\prime}\right)_{\text {min }}=3.14 p s i, t_{r 2}=$ $35.6 \mathrm{hrs}, \mathrm{P}_{\mathrm{r} 2}=232.4 \mathrm{psi} .=0.071$ and 0.011 were estimated from the first and second radial flow, respectively, by using Eq. 7. Eq. 8 allowed an estimation of $=2.73 \times 10^{-7}$ only for the first radial flow. For the second radial flow the condensate rate is unknown then Eq. 8 does not apply here. From the application of Eq. 10 , a skin factor of -0.76 was estimated. Notice that skin factor from the second radial flow should not be estimated from Eq. 11 since neither condensate viscosity nor condensate flow rate are known. All we can say is that a sharp reduction in flow capacity is virtually seen for the increase in both the pressure derivative and the pressure drop value.

Observe in table 2 that the values obtained from the TDS technique agree well with the input ones. Notice how the naturally fractured reservoir parameters and permeability are affected when Nc effects are excluded.

\section{Variation of and}

Fig. 10 was generated for $0.02 \quad 0.2$ when Nc effect are considered. There, we can appreciate that as increases, it is easier to see the early radial flow regime. This causes a reduction of the transition zone until it fully disappears as approaches the unity. It is difficult to see the condensate formation since it takes place at the end of second radial flow regime at about $30 \mathrm{hrs}$.
In Fig. 11 we observe the behavior of the pressure derivative for $3 \mathrm{E}-6 \quad 5 \mathrm{E}-7$. The smaller the value, the longer the early radial flow line. Condensate formation occurs at the end of the transition dominated flow for $=5 \mathrm{E}-7,7 \mathrm{E}-7$ and $1 \mathrm{E}-6$, and it takes place during the second radial flow period for values of $2 \mathrm{E}-6$ and $3 \mathrm{E}-6$, at about $20 \mathrm{hrs}$. Under Nc effects it is difficult to distinguish the single phase and two phase zones.

\section{Conclusions}

1. Liquid formation in gas condensate naturally fractured condensate occurs in more quantity in the fracture because of the higher pressure drop- than in the matrix. Considering the Nc effects a significant reduction in condensate saturation will occur with a consequent increment of gas relative permeability.

2. The higher the capillary number, the lower the condensate saturation and the higher the gas relative permeability due to a reduction of interfacial tension which implies a better preference for gas flow in the reservoir. Condensate formation is so small that it is not reflected in the pressure derivative curve. Also, pressure drop is positively affected since it is lower than the case of excluding capillary number effects.

3. TDS technique was used to estimate reservoir parameters. We found that the capillary number effects alter the estimation of the naturally fractured reservoir parameters and the estimation of effective permeability and skin factor because an extra pressure drop and an increase in the pressure derivative curve take place. Estimation of these parameters, although possible, should not be performed because condensate rate and viscosity change.

\section{Acknowledgments}

The authors gratefully acknowledge the financial support of the Colombian Petroleum Institute, ICP, under the mutual agreement Number 008 signed between this institution and Universidad Surcolombiana.

Nomenclature

$\begin{array}{ll}B & \text { Oil volumetric factor } \\ c_{t} & \text { Total compressibility, } \mathrm{psi}^{-1} \\ h & \text { Thickness, } \mathrm{ft} \\ n_{g} & \text { Corey's exponent for the gas phase } \\ n_{o} & \text { Corey's exponent for the oil phase } \\ k & \text { Permeability, md } \\ k_{f b \_}{ }_{b_{o}} k_{r g}^{o} & \text { Condensate effective permeability in the fracture bula system, } \mathrm{md} \\ k_{r j v} & \text { End-point relative permeabilities } \\ L & \text { Relative permeability modified by } N_{c j} \text { of the } \mathrm{j}^{\text {th }} \text { phase in the flow direction } \\ P & \text { at a previous time level } \\ q & \text { Grid length in the flow direction, } \mathrm{ft} \\ q_{g} & \text { Pressure, psi } \\ S & \text { Condensate rate, BPD } \\ S_{j} & \text { Gas flow rate, MMscf/d } \\ & \text { Saturation } \\ & \text { Normalized phase saturation }\end{array}$

\author{
Skin factor \\ Residual gas saturation \\ Residual oil saturation \\ Time \\ Pressure derivative, psi \\ Velocity, ft/sec \\ Warren and Root's storativity coefficient \\ Warren and Root's interporosity flow parameter
}




\section{Greek}

\begin{tabular}{|l|l|}
\hline$\Delta$ & Change, drop \\
\hline$\Delta P_{j}$ & Pressure drop of the $\mathrm{j}^{\text {th }}$ phase in the flow direction, psi \\
\hline$\phi$ & Porosity \\
\hline$\mu$ & Viscosity, cp \\
\hline$\sigma$ & Oil-gas interfacial tension, dyne/cm \\
\hline
\end{tabular}

\section{Suffixes}

\begin{tabular}{|l|l|}
\hline$f$ & Fracture \\
\hline$f b$ & Fracture bulk \\
\hline$g$ & Gas \\
\hline$m$ & Matrix \\
\hline$m i n$ & Minimum \\
\hline$o$ & Oil \\
\hline$r$ & Radial, Residual \\
\hline$r 1$ & First radial flow \\
\hline$r 2$ & Second radial flow \\
\hline$t$ & Total \\
\hline$w$ & Well \\
\hline
\end{tabular}

\section{References}

BARRIOS, K., STEWART, G. and DAVIES, D., 2003. "A Novel Methodology for the Analysis of Well Test Responses in Gas Condensate Reservoirs", paper SPE 81039 presented at the SPE Latin American and Caribbean Petroleum Engineering Conference held in Port of Spain, Trinidad, West Indies, 27-30 April, 2003.

BENGHERBIA, M. and TIAB, D., 2002. "Gas-Condensate Well Performance Using Compositional Simulator". SPE 75531 Presented at the SPE Gas Technology Symposium held in Calgary, Alberta, Canada, 30 April-2 May, 2002.

ENGLER, T. and TIAB, D., 1996. "Analysis of Pressure and Pressure Derivative without Type Curve Matching, 4. Naturally Fractured Reservoirs". Journal of Petroleum Science and Engineering 15 (1996) p. 127-138.

FEVANG, $\varnothing$ and SINGH, K., 2000. "Guidelines for Choosing Compositional and Black-Oil Models for Volatile Oil and GasCondensate Reservoirs" Paper SPE 63087 Presented at the 2000 SPE Annual Technical Conference and Exhibition held in Dallas, Texas, 1-4 October 2000.
GRINGARTEN, A.C., AL-LAMKI, A., DAUNGKAEW, S., 2000. "Well Test Analysis in Gas-Condensate Reservoirs", paper SPE 62920 presented at the 2000 SPE Annual Technical Conference and Exhibition held in Dallas, Texas, 1-4, 0ct.. 2000.

KOOL, H., AZARI, M., SPE, SOLIMAN, M.Y., PROETT, M.A., IRANI, C.A., and DYBDAHL, B., 2001. "Testing of Gas Condensate Reservoirs - Sampling, Test Design and Analysis" SPE 68668 Presented at the SPE Asia Pacific Oil and Gas Conference and Exhibition held in Jakarta, Indonesia, 17-19 April 2001.

SUAZA, I.M. and GARCIA, H., 2006. "Análisis Del Comportamiento de la Presión y Derivada de Presión para un Pozo Vertical en Yacimientos Naturalmente Fracturados de Gas Condensado". B.S. Thesis. Universidad Surcolombiana.

MUNOZ, O.F., ESCOBAR, F.H., AVILEZ, H.F., SEPULVEDA, J.A, and CANTILLO, J.H., 2006. "Effect of Non-Darcy Flow and Capillary Number on Well Tests of Gas Condensate Reservoirs". Paper SPE 100818 prepared for presentation at the 2006 SPE Asia Pacific Oil \& Gas Conference and Exhibition held in Adelaide, Australia, 11-13 September 2006. 
Table 1. Input data used in the simulation

\begin{tabular}{|l|c|}
\hline \multicolumn{1}{|c|}{ Parameter } & Value \\
\hline Reservoir thickness, $\mathrm{ft}$ & 100 \\
\hline Reservoir radius, $\mathrm{ft}$ & 2000 \\
\hline Reservoir depth, $\mathrm{ft}$ & 15000 \\
\hline Matrix Permeability, md & 0.00048 \\
\hline Fracture Permeability, md & 30 \\
\hline Matriz porosity, \% & 18.8 \\
\hline Fracture porosity, \% & 1.2 \\
\hline Reservoir inicial pressure pressure, $\mathrm{psi}$ & 5300 \\
\hline Wellbore radius, $\mathrm{ft}$ & 0.25 \\
\hline Reservoir Temperatura, ${ }^{\circ} \mathrm{F}$ & 320 \\
\hline
\end{tabular}

Table 2. Comparison of results

\begin{tabular}{|c|c|c|c|c|c|}
\hline \multirow[b]{2}{*}{ PARAMETER } & \multirow[b]{2}{*}{$\begin{array}{c}\text { INPUT } \\
\text { VALUES }\end{array}$} & \multicolumn{2}{|c|}{ Including $N c$} & \multicolumn{2}{|c|}{ Excluding $N c$} \\
\hline & & $\begin{array}{l}\text { From } 1^{\text {st }} \\
\text { radial flow }\end{array}$ & $\begin{array}{l}\text { From } 2^{\text {nd }} \\
\text { radial flow }\end{array}$ & $\begin{array}{l}\text { From } 1^{\text {st }} \\
\text { radial flow }\end{array}$ & $\begin{array}{l}\text { From } 2^{\text {nd }} \\
\text { radial flow }\end{array}$ \\
\hline$k_{f b}, \mathrm{md}$ & 30 & \multicolumn{2}{|c|}{37.9} & 35.7 & N.C. \\
\hline$\omega$ & 0.06 & \multicolumn{2}{|c|}{0.071} & 0.071 & 0.011 \\
\hline$\omega$ & $7 \times 10^{-7}$ & \multicolumn{2}{|c|}{$2.48 \times 10^{-7}$} & $2.73 \times 10^{-7}$ & N.C. \\
\hline$s$ & 0 & -0.49 & -0.49 & -0.76 & N.C. \\
\hline
\end{tabular}

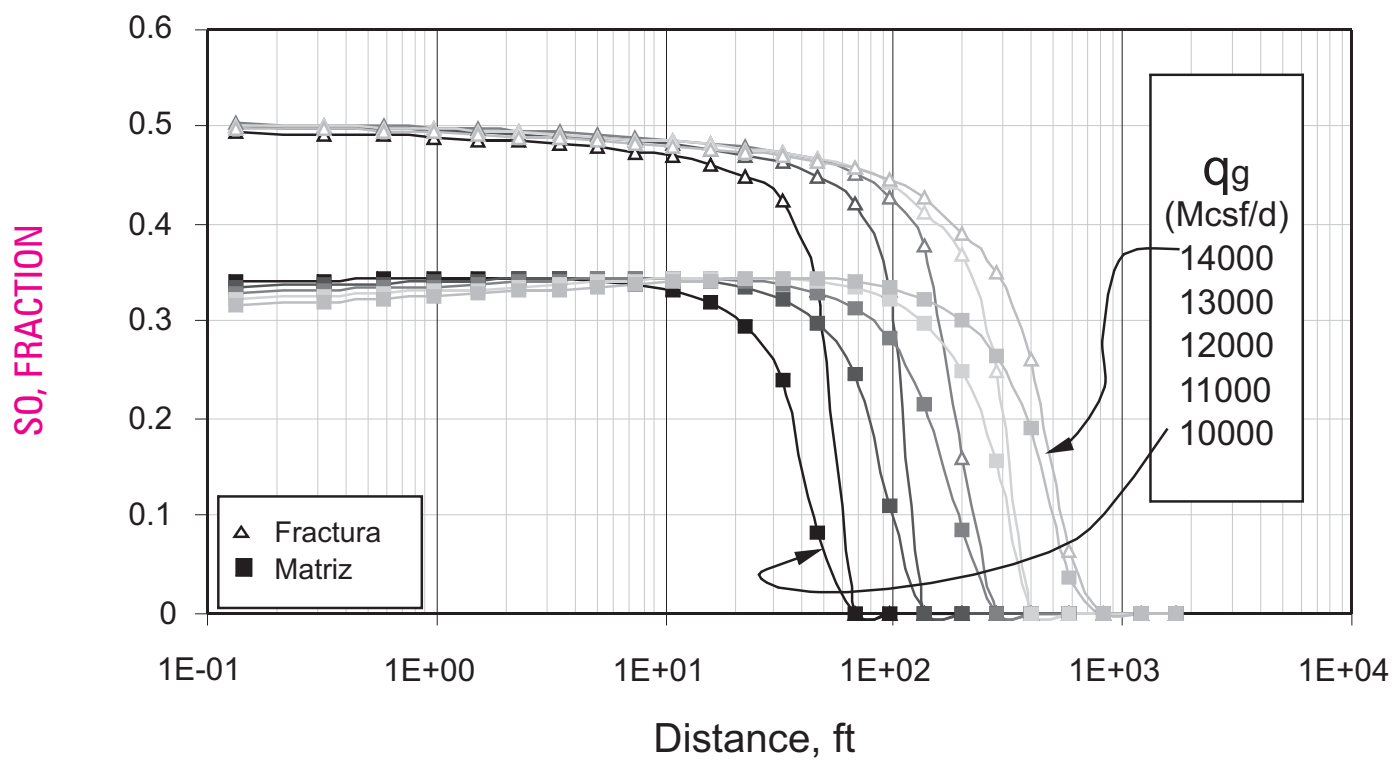

Fig. 1. Condensate saturation profile for different gas flow rates without capillary number effects 


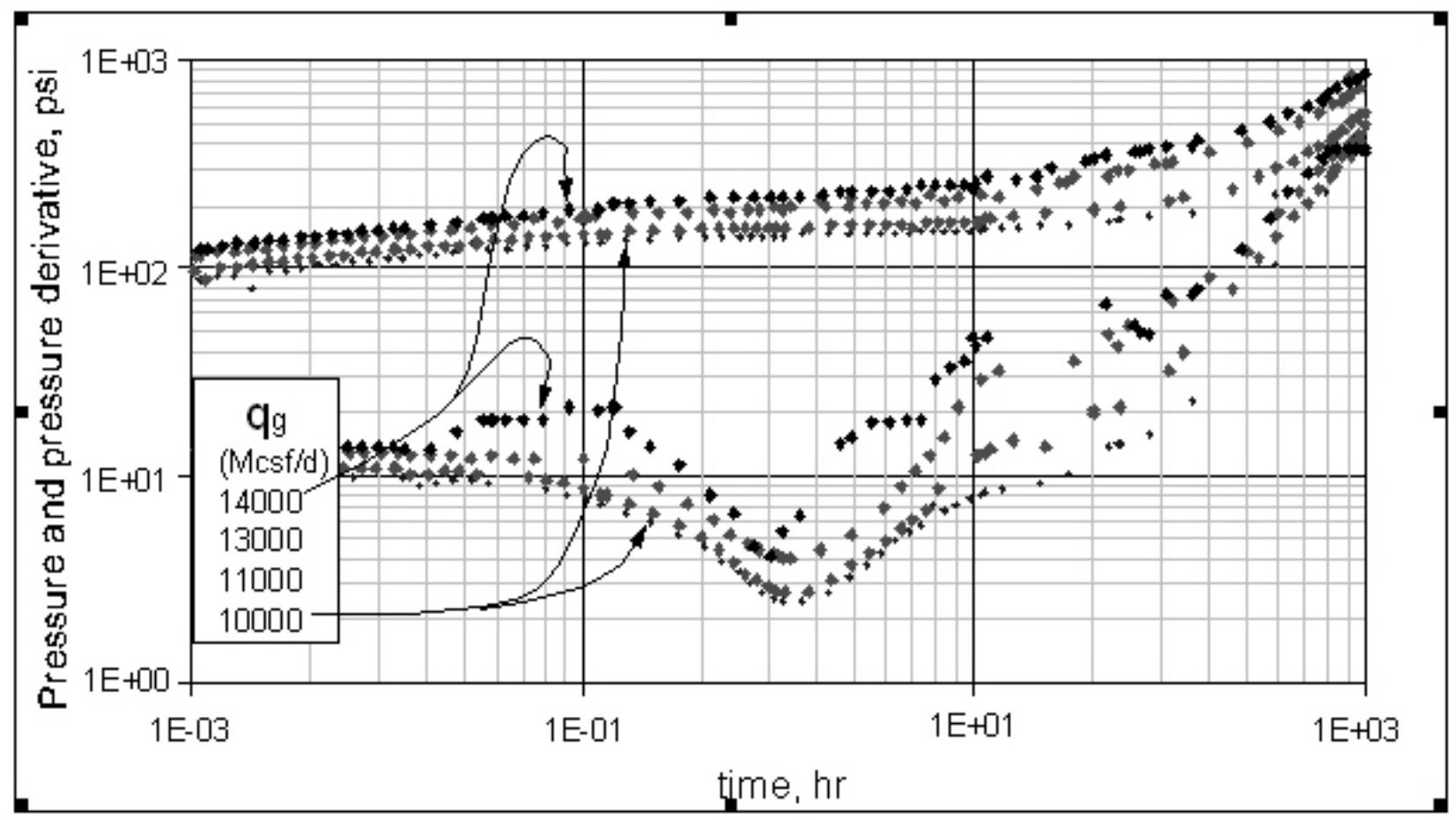

Fig. 2. Pressure and pressure derivative behavior for different gas flow rates

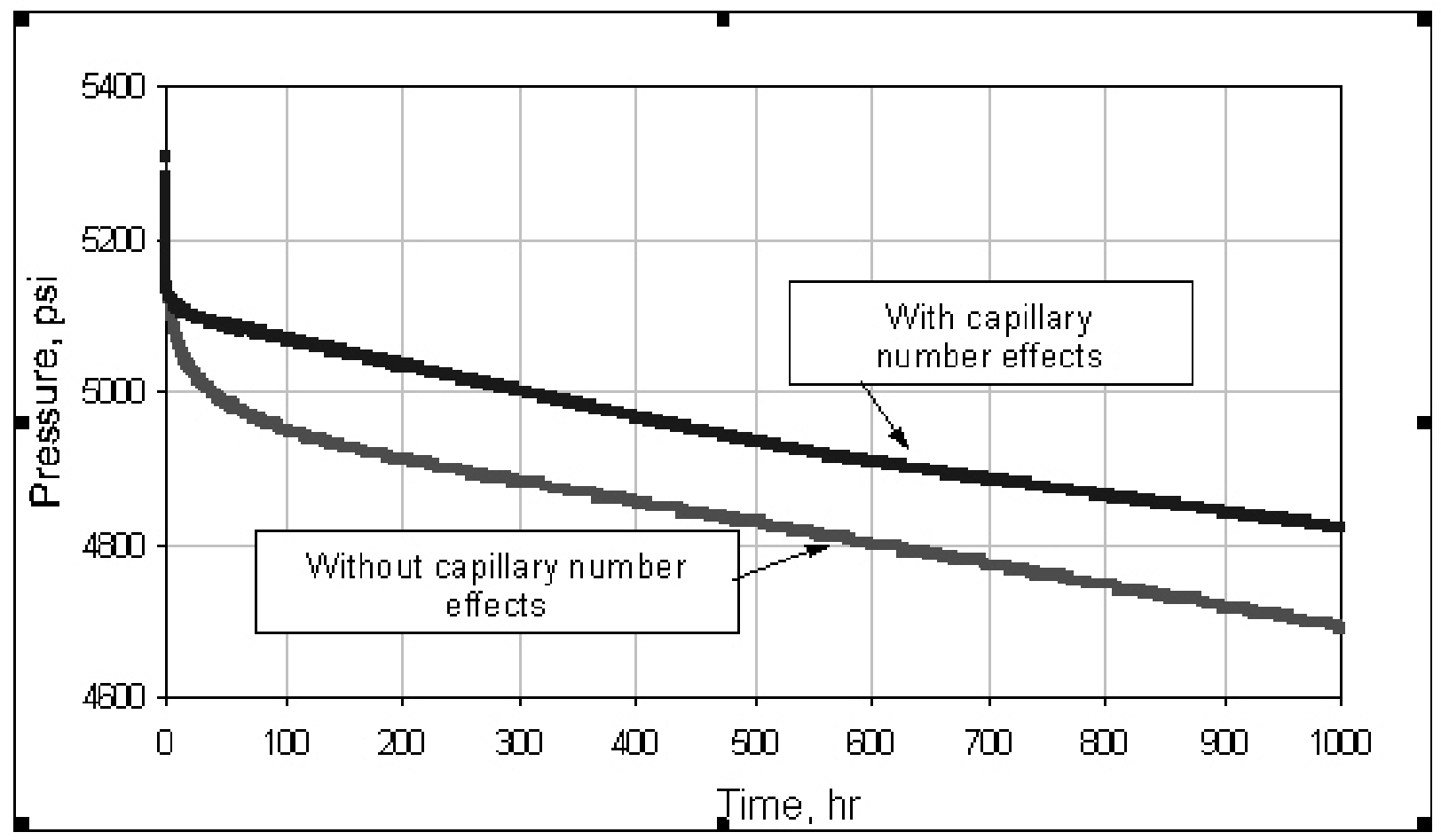

Fig. 3. Well pressure behavior with and without capillary number effects 


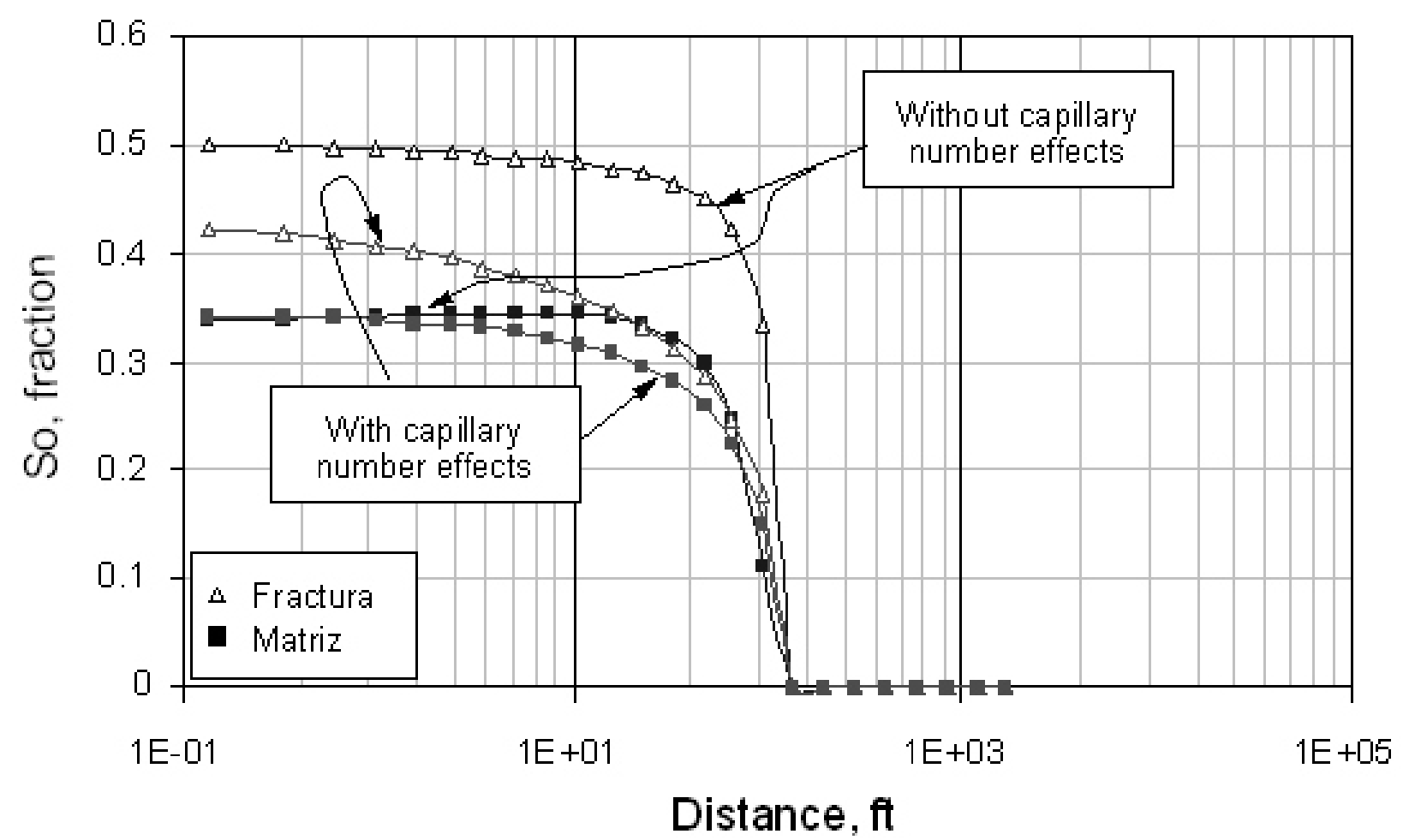

Fig. 4. Condensate saturation profile with and without capillary number effects

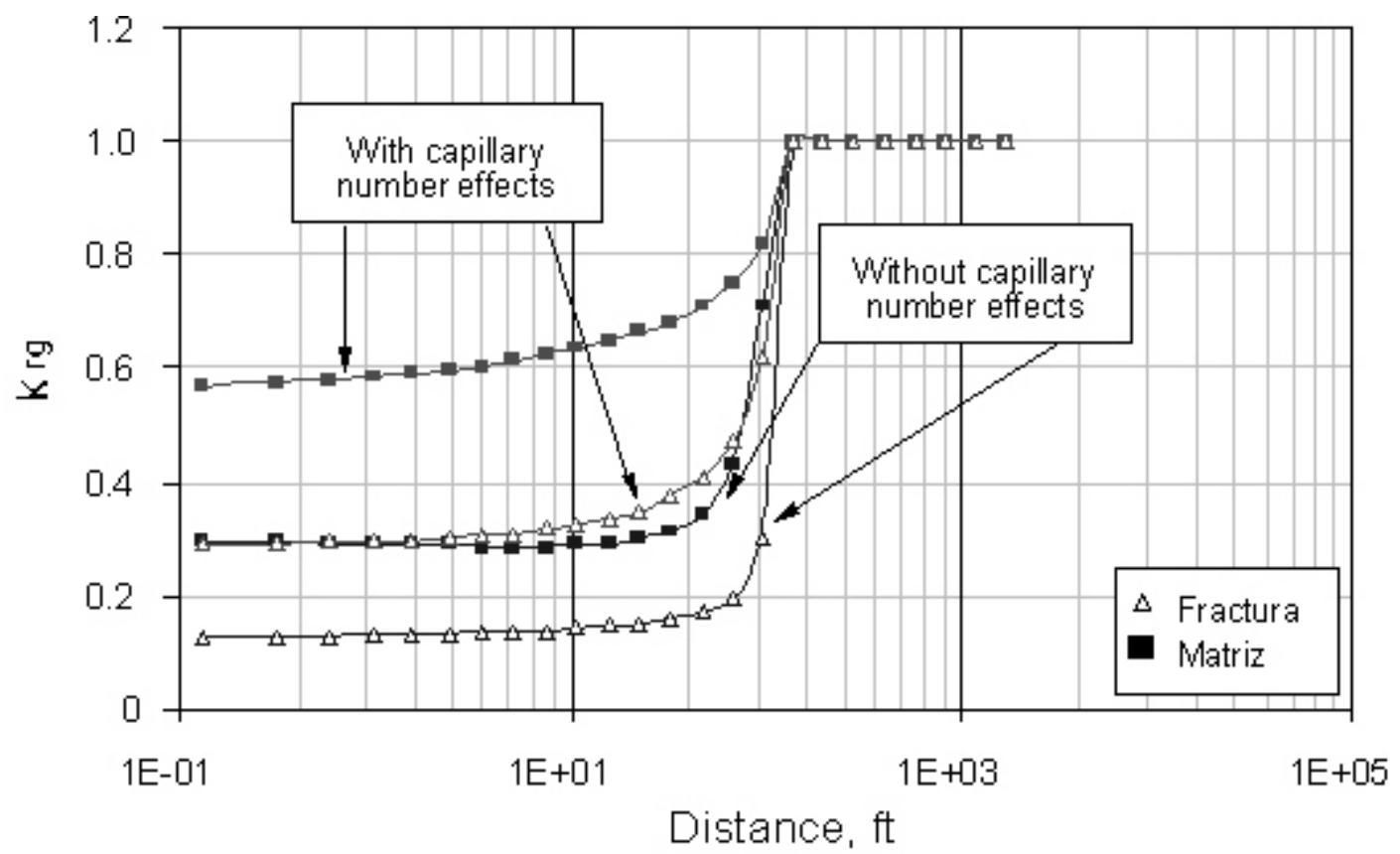

Fig. 5. Gas relative permeability with and without capillary number effects for the fracture-matrix system with a $q_{g}=11000 \mathrm{Mscf} / \mathrm{d}$ 


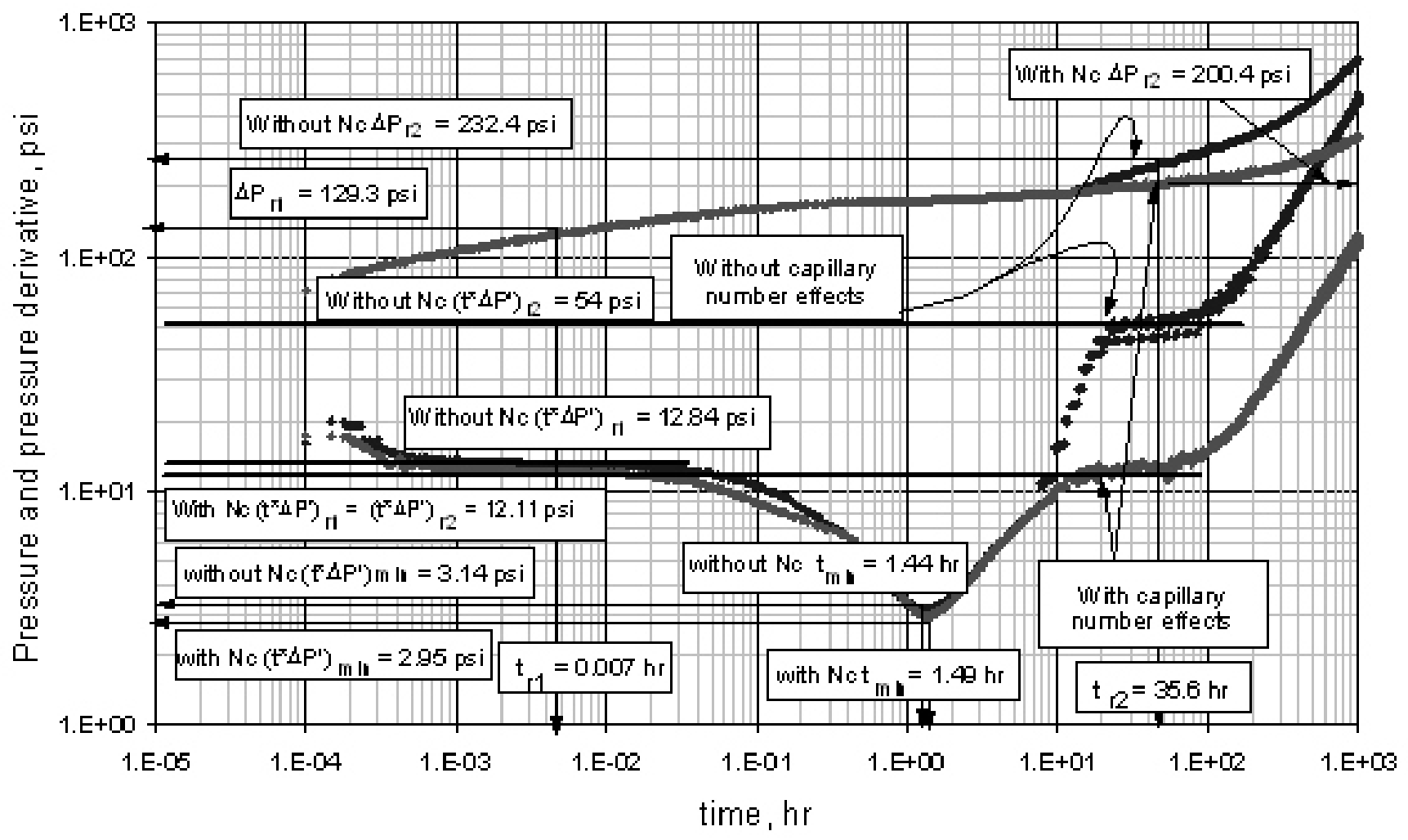

Fig. 6. Pressure and pressure derivative plot for $q_{g}=11000 \mathrm{Mscf} / \mathrm{d}$ with and without capillary number effects

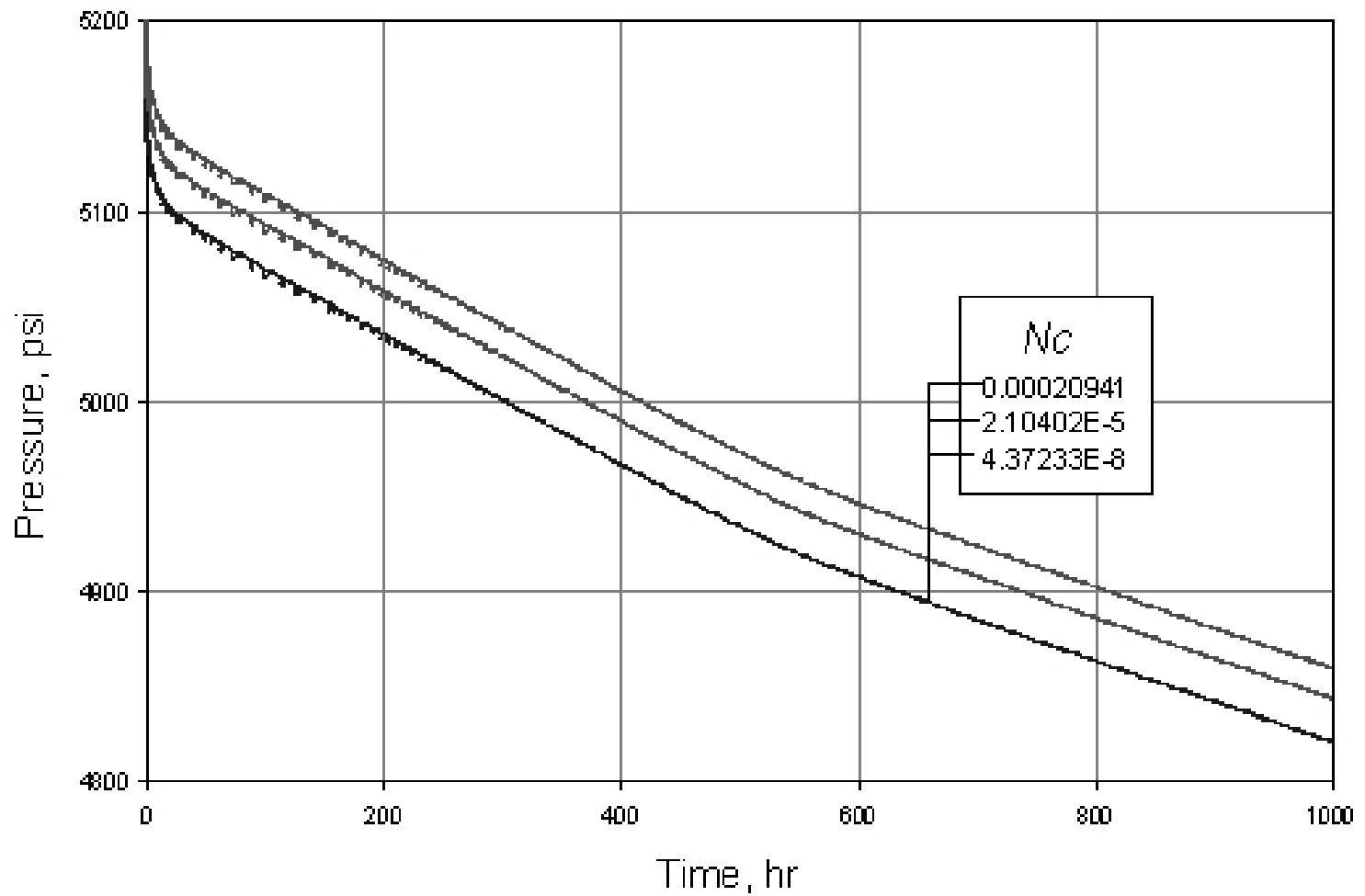

Fig. 7. Well pressure behavior for different capillary numbers 


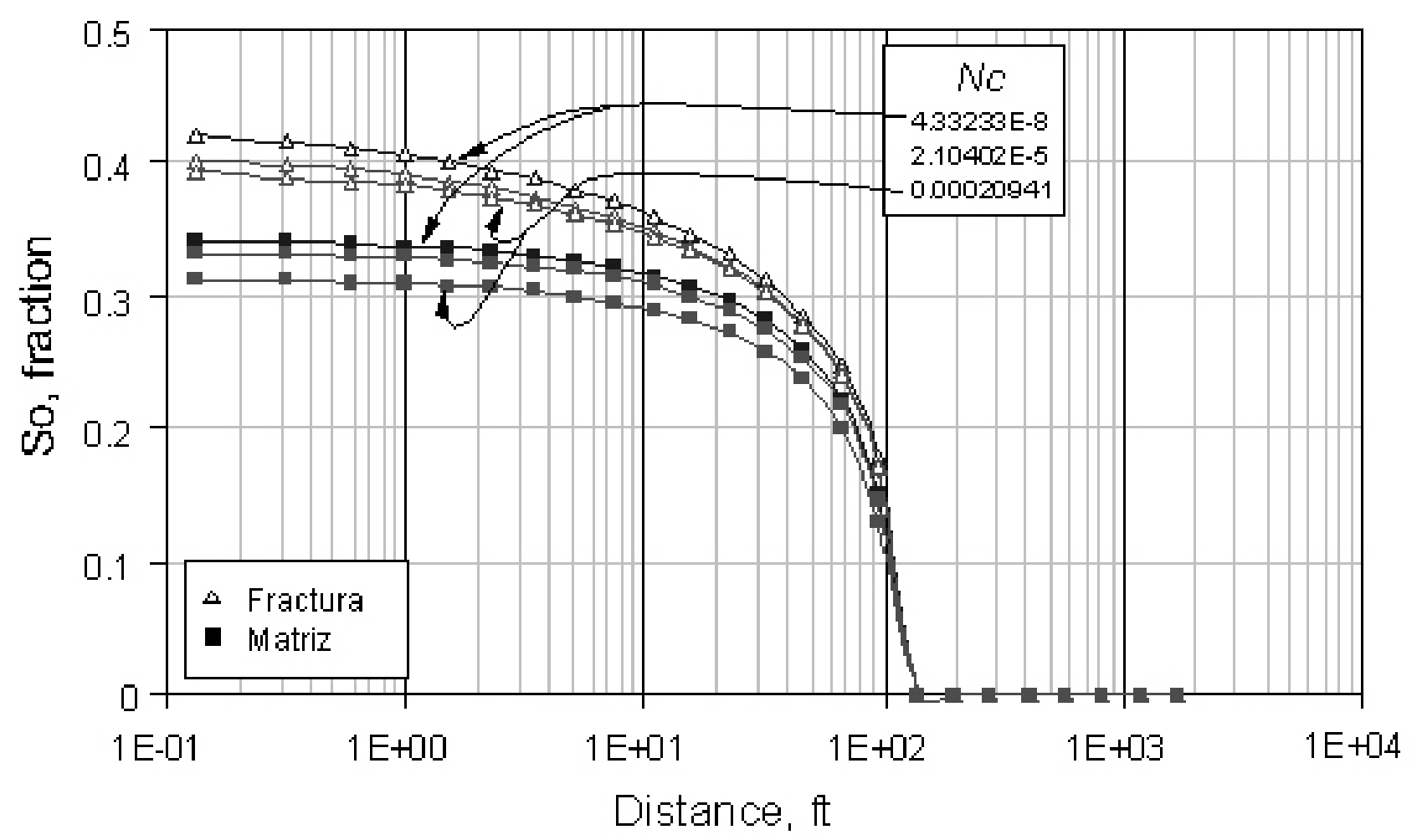

Fig. 8. Condensate profile saturation for different capillary number values

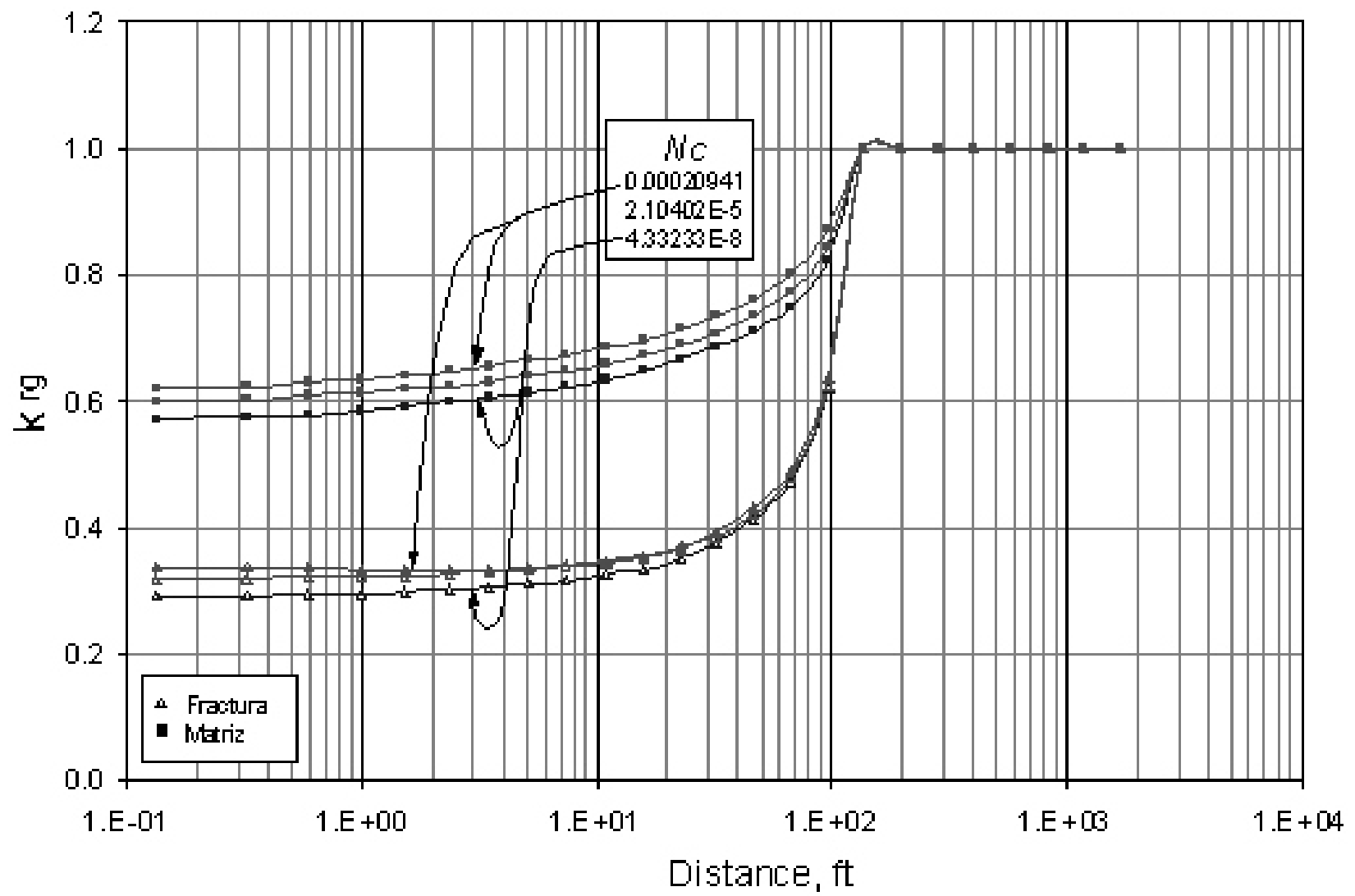

Fig. 9. Gas relative permeability profile for different Nc's and $q_{g}=11000 \mathrm{Mscf} / \mathrm{d}$ 


\section{Fig. 9. Gas relative permeability profile for different $N c^{\prime} \mathrm{S}$ and $g_{g}=11000 \mathrm{Mscfld}$}

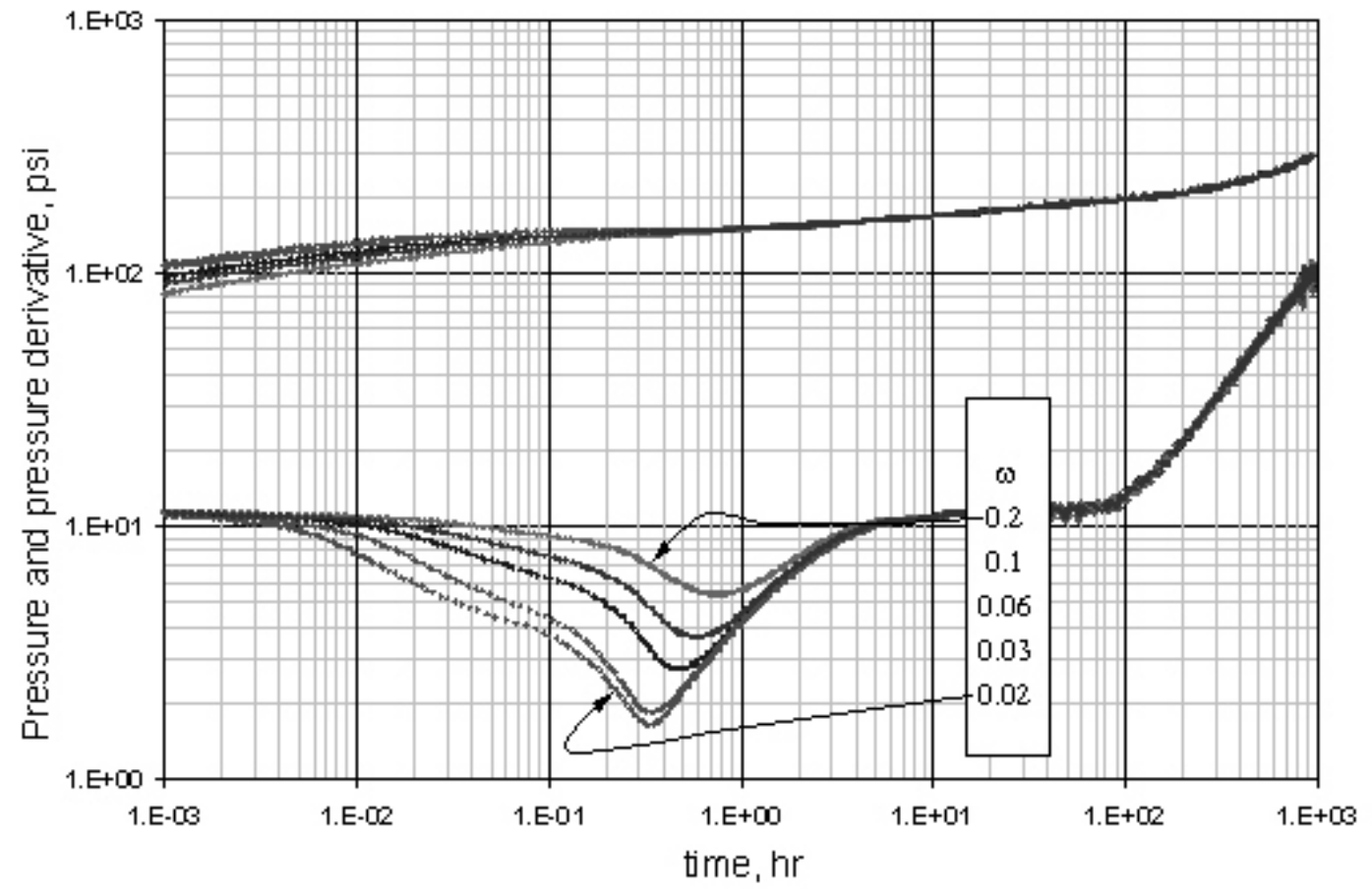

Fig. 10. Pressure and pressure derivative plot for $\mathrm{q}_{\mathrm{g}}=11 \mathrm{MMscf} / \mathrm{d},=7 \mathrm{E}-7$ and different values of 


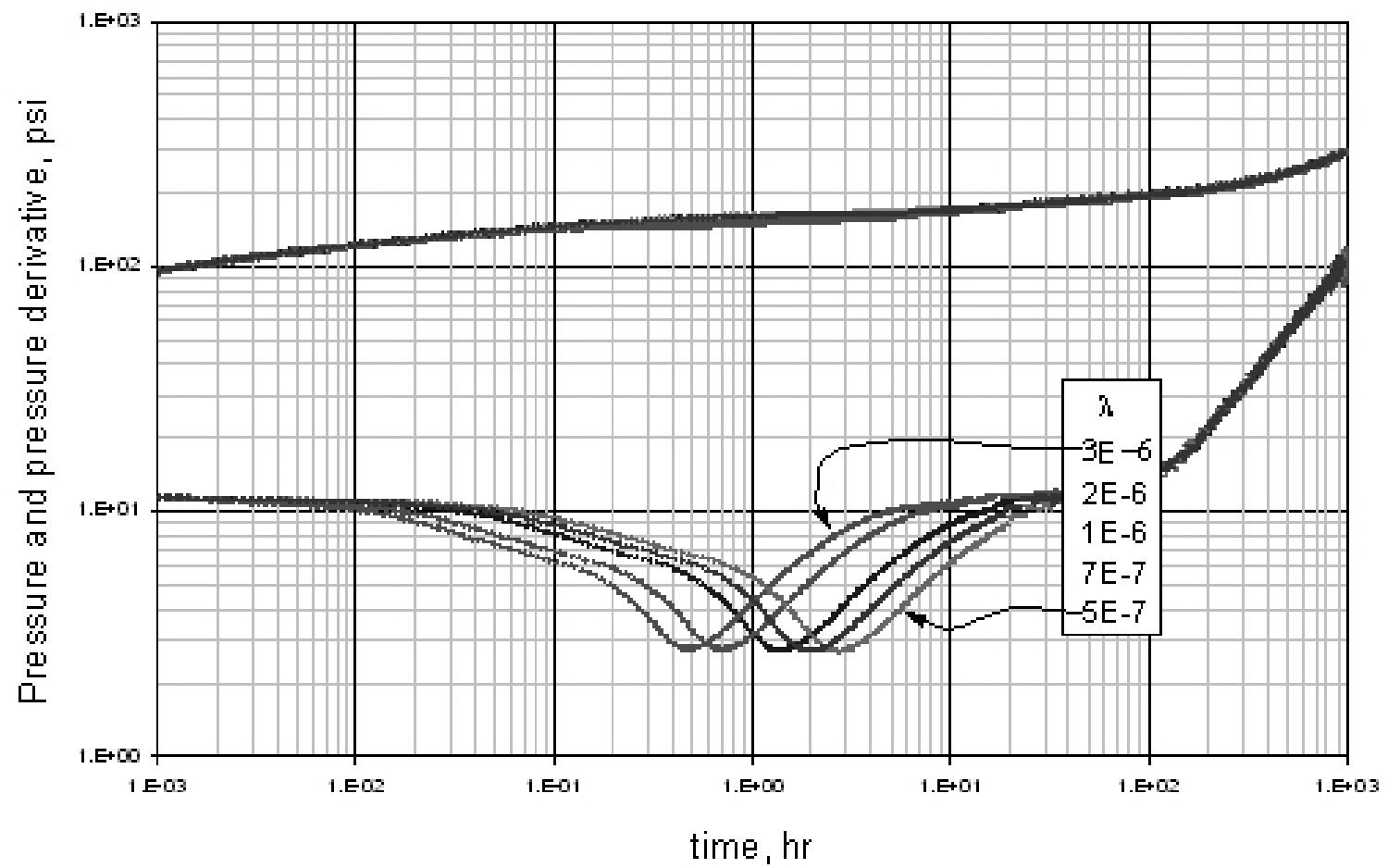

Fig. 11. Pressure and pressure derivative plot for $\mathrm{q}_{\mathrm{g}}=11 \mathrm{MMscf} / \mathrm{d},=7 \mathrm{E}-7$ and different values of 